\title{
PHYSICAL ACTIVITY AND SCREEN TIME: A CROSS-SECTIONAL STUDY IN ALIGARH, NORTH INDIA
}

\author{
Sameena Ahmad ${ }^{1}$, M. Athar Ansari' ${ }^{2}$, Salman Khalil $^{3}$, Ali Jafar Abedi ${ }^{4}$, Mohd. NajmulAqib Khan ${ }^{5}$ \\ ${ }^{1}$ Junior resident, ${ }^{2}$ Professor, ${ }^{3}$ Associate Professor, ${ }^{4}$ Assistant Professor, Department of community medicine, \\ Jawaharlal Nehru Medical College, Aligarh Muslim University, Aligarh, India \\ ${ }^{5}$ Assistant Professor, Department Of Community Medicine, Government Medical College, Haldwani, \\ Uttarakhand, India \\ Corresponding author: Ali JafarAbedi \\ Email: alijafarabedi@gmail.com
}

\begin{abstract}
Children have been exposed to electronic devices. They grow up thinking that these devices are a part of their daily lives. As they get older, their dependency on such devices grows, even during school days. As a result, their physical activity is hardly handled even until they reach adulthood. This study assessed the frequency of physical activity, duration of screen time, and association between these variables amongst school children. This crosssectional study was conducted among 800 school-based adolescents aged 12 to 14 years at A.M.U. High Schools, Aligarh, in July 2018 to June 2019. Students were asked about their physical activity and screen habits by disseminating a self- reported questionnaire. The data were analyzed in SPSS version 20.0. The study found that most of the students had adequate physical activities (75.51\%), while the reported screen time duration was also adequate for most $(59.1 \%)$. The association between the two variables was not statistically significant $(\mathrm{p}>0.05)$. For the students with inadequate frequency of physical activity and enough duration of screen time, interventions should be done both at family and school levels to make them more physically active and better at performing studies and reaping the benefits of good health.
\end{abstract}

Keywords: physical activity, school children, adolescents, screen time

\section{INTRODUCTION}

The benefits of physical activity at all age groups, right from childhood, have been well documented. Adolescence, particularly, is a critical period of development during lifetime in which behavior patterns and lifestyle choices i.e., being physically active are established. There has been ample research that can demonstrate the advantages of being physically active, as well as the health effects of less physical activities and more sedentary behaviour (Kumar, Robinson and Till, 2015).There has been growing evidence about positive impacts of physical activity on child's social and cognitive development carrying forward to adulthood (Organization, 2019). The first ever global trends for adolescents with inadequate physical activity indicate that increment in physical activity between 11 to 17 years adolescents must be given urgent attention (Guthold, Stevens, Riley et al., 2018).

The trend and frequency of physical activity in children and adolescents in developing countries have been analyzed in depth (McKenzie, Marshall, Sallis et al., 2000; Sallis, Prochaska and Taylor, 2000); however, there is a dearth of documentation for the same in developing countries, particularly Asian. Nowadays, frequency of physical activity in children decreases due to various factors, e.g., changes in lifestyles such as watching television, playing games on computer or mobile phones for long hours, to name a few. It has also been known that excessive exposure of screen time can cause a tendency to overuse of such electronic devices later in the next development phase and interruption of healthy routine, whilst also affecting studies at the same time (Canadian Paediatric Society, 2017). 
Besides, children do not compensate for physical activities after school, while chances for doing physical activities are restricted during the school day. Along with decreased frequency of physical activity, longer screen time puts the children at risk of various health issues such as overweight, blood sugar problems, decreased social interaction, and others (Kang, Lee, Shim et al., 2010; Sisson, Broyles, Baker et al., 2010). Additional school-based physical activities may be warranted to engage children even beyond physical education classes (Ronghe, Gotmare and Kawishwar, 2016). In view of this, it was thought that it was important to carry out an assessment of frequency of physical activity, the duration of the screen time, and the association between these variables in school children aged 12 to 14 years. By doing this study, it accounts for preventive measures that could be placed in time to avoid the incidence of overweight later in adulthood.

\section{METHODS}

The current study was conducted across high schools of Aligarh Muslim University (AMU), Aligarh, a city in the North India, from July 2018 to June 2019. Selected schools had recess during the working days, along with physical education classes in their curriculum. The AMU currently maintains six high schools, including three male and three female schools.

A cross-sectional design was used as the research approach. The participants were selected using simple random sampling with a table of random numbers which students could choose. The selected students were aged between 12 to 14 years and had to be present on the day of examination and had willingness to participate in the examination. Whereas, the exclusion criteria were children aged less than 12 years and more than 15 years, not willing to participate, absent on the day of examination, uncooperative, and suffering from chronic illness, endocrinal problems, physical and mental problems.

The study was carried out after getting the approval of the Research Ethical Committee, Faculty of Medicine, Aligarh Muslim University. Written consent was obtained prior to the research from the principals of the relevant schools through the School Education Directorate of AMU. The respondents informed their consent for participation orally. Those who did not give consent were excluded from the research. Students were assured about the confidentiality of the information and their identity during the examination and interview. If a medical problem was diagnosed, the respondent would receive appropriate medical advice. Health education and advice would be provided to all respondents.

Taking prevalence of physical inactivity at $21 \%$ (Nawab, Khan, Khan et al., 2016), absolute permissible error at $3 \%$ with a confidence level of $95 \%$, and a non-response rate at $10 \%$, the sample size (n) amounted to 709, which were rounded off to 800. Simple random sampling with probability proportionate to size (PPS) was used to draw the sample size.

The study instrument included pretested questionnaires regarding details of socio-demographic variables and screen time and physical activity questionnaires for older children (PAQ-C) aged 8-14 years (grades 4-8). It could be used among those children present in the school system which had recess in their daily work schedule. The questionnaires had been tested for reliability and finally obtained a high internal consistency (0.96) for final PAQ-C score. The highest correlation was found in item 9 (rho $=0.311 ; \mathrm{p}<0.01$ ) (BenítezPorres et al., 2016). Significantly moderate correlation was found in moderate physical activity (MPA) $(r=0.462 ; p<0.001)$ and moderate to vigorous physical activity (MVPA) ( $\mathrm{r}=0.483$; $\mathrm{p}<0.001)$; physical activity assessment was done through PAQ$S$ (Physical Activity Questionnaire for Smaller Children). The validity of PAQ-S 
for the estimation of MPA and MVPA was found to be almost similar to the selfreported measures for schoolchildren (Manios et al., 2013).

Screen time was defined as screen viewing, including the use of any electronic devices such as tablets, smartphones, video games, television, wearable technology, or computer. It has been reported that children 11-14 years old, on an average, spend about 9 hours a day in front of screen, while it should not be more than 2 hours per day (Encyclopedia, 2020).

Regarding anthropometric measurements, Body Mass Index (BMI) was measured with an electronic weighing machine, which was kept on a firm horizontal surface. The respondents were asked to stand upright, lean their back against the wall, move the heels closer one another without shoes, and looking at a horizontal plane. Children with BMI of $>+1$ $\mathrm{SD}$ (equivalent to BMI $25 \mathrm{~kg} / \mathrm{m}^{2}$ ) are categorized overweight. Similarly, underweight is labelled to children with BMI < 1 SD according to the WHO growth charts (5-19 years) for adolescents (World Health Organization, 2020).

The interview schedule was pretested by performing a pilot study on $10 \%$ of the sample size to assess the feasibility and appropriateness of the research instruments and methods. Based on the pretest, the interview schedule was modified as per response elicited, and the words used in the questionnaire were simplified to make them more understandable. Completed schedules were checked weekly for consistency and completeness by the supervisors. Data were analyzed using SPSS version 20.0 (Chicago, IL, United States) for Windows.

The Chi-square test was applied to study the association between physical activity and screen time among children. A statistical significance level (p) was set at $<$ 0.05 . (to ethical clearance number D. No. 1006/FM dated 13.7.2018)

\section{RESULTS}

This section explains sociodemographic characteristics of the respondents.

Table 1 shows that the majority $(42.6 \%)$ of the respondents was in the 12year age group as new academic session just started at the time of study. The mean age of the respondents was between $12 \pm 0.81$ years. In the present study, $56.6 \%$ of the respondents were males, and $43.4 \%$ were females. As many as $92.4 \%$ lived in urban areas, while $7.6 \%$ students lived in rural areas.

Table 1. Sociodemographic characteristics of the respondents

\begin{tabular}{lcc}
\hline $\begin{array}{l}\text { Characteristi } \\
\text { cs }\end{array}$ & $\begin{array}{c}\text { Frequenc } \\
\mathbf{y}(\mathbf{N})\end{array}$ & $\begin{array}{c}\text { Percentag } \\
\text { e }(\mathbf{\%})\end{array}$ \\
\hline Age in years & & \\
\hline 12 & 341 & 42.6 \\
\hline 13 & 244 & 30.5 \\
\hline 14 & 215 & 26.9 \\
\hline Sex & & \\
\hline Male & 453 & 56.6 \\
\hline Female & 347 & 43.4 \\
\hline Address & & \\
\hline Urban & 739 & 92.4 \\
\hline Rural & 61 & 7.6 \\
\hline
\end{tabular}

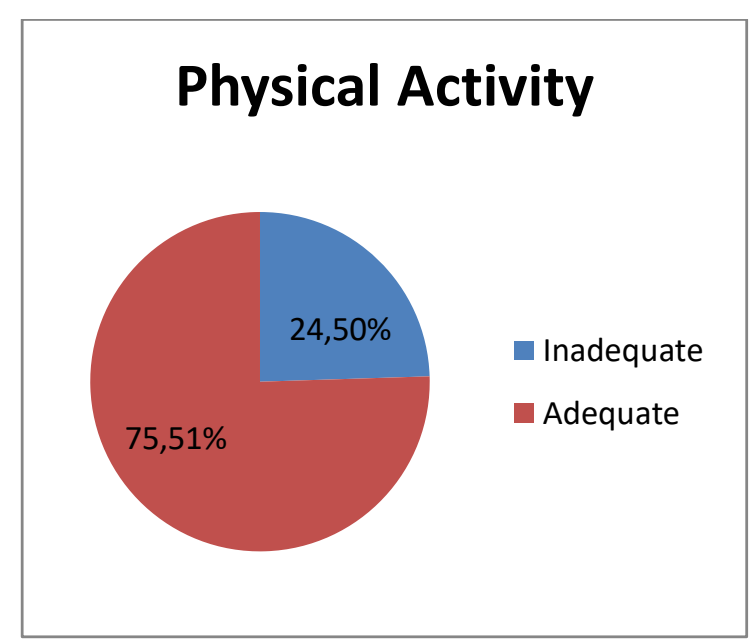

Figure 2. Distribution of students at A.M.U. High Schools by frequency of physical activity 
Figure 2 presents the majority of the adolescent respondents had adequate frequency of physical activity (75\%). Meanwhile, inadequate frequency of physical activity was reported among a quarter of the students. It can be concluded that students with adequate frequency of physical activity met the minimum required criteria for physical activity, while students with inadequate frequency of physical activity could be at risk of various diseases which arise due to less physical activity.

Very few students $(8.30 \%)$ reported that they did not have enough time to watch television mainly due to their packed study schedule or coaching or tuition classes. A few students $(24 \%)$ reported that they watched television for more than 2-3 hours, and very few $(8.6 \%)$ informed having screen time of more than 4 hours, while the majority $(59.10 \%)$ had screen time of $1-2$ hours (see Figure 3). Hence, it can be concluded that screen time duration could mainly depend on the time left after school and coaching classes. The total mean screen time was $2.6 \pm 0.94$ hours per day.

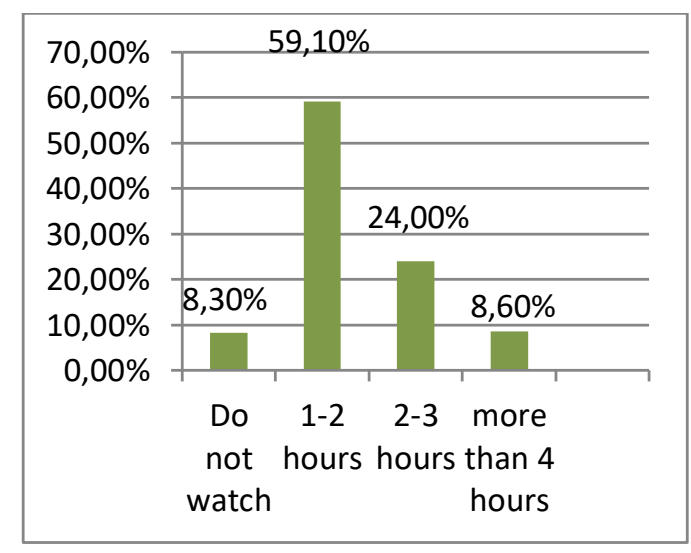

Figure 3. Distribution of students at A.M.U. High Schools by device screen time

Table 2. The average duration of screen time by variables among students at A.M.U. High Schools

\begin{tabular}{|c|c|c|}
\hline Sex & $\mathbf{N}$ & Mean screen time duration \\
\hline Males & 453 & $2.40 \pm 1.23$ hours \\
\hline Females & 347 & $2.31 \pm 1.16$ hours \\
\hline \multicolumn{3}{|c|}{$\mathrm{t}=0.9 ; \mathrm{p}<0.05$} \\
\hline Age & $\mathbf{N}$ & Mean screen time duration \\
\hline 12 years & 341 & $2.6 \pm 0.90$ hours \\
\hline 13 years & 244 & $2.8 \pm 1.03$ hours \\
\hline 14 years & 215 & $2.6 \pm 0.89$ hours \\
\hline \multicolumn{3}{|c|}{ ANOVAF $=3.38 ; \mathrm{p}<0.05$} \\
\hline BMI & $\mathbf{N}$ & Mean Screen time Duration \\
\hline Underweight & 415 & $2.6 \pm 0.96$ hours \\
\hline Normal & 204 & $2.6 \pm 0.94$ hours \\
\hline Overweight & 181 & $2.6 \pm 0.90$ hours \\
\hline \multicolumn{3}{|c|}{ ANOVA F $=0.167 ; p>0.05$} \\
\hline
\end{tabular}

Table 2 presents that the mean screen time had a statistically significant association with gender as the T-test showed the mean screen time was not much different among males from females (2.40 \pm 1.23 and 2.31 \pm 1.16 , respectively). Regarding the age groups, the ANOVA test found age was significantly related to screen time duration. The mean screen time was not much different among the three age groups (2.6 \pm 0.90 hours among 12-year-old students, $2.8 \pm 1.03$ hours among 13-yearold students, and 2.6 \pm 0.89 hours among 14year-old students). While the BMI was not significantly different from the mean screen time (2.6 \pm 0.96 hours among underweight students, 2.6 \pm 0.94 hours normal students, and 2.6 \pm 0.90 hours among overweight students). 
Table 3. The association between frequency of physical activity, age, sex, BMI and screen time among students at A.M.U. High Schools

\begin{tabular}{|c|c|c|c|c|c|c|}
\hline \multirow{3}{*}{ Age } & \multicolumn{4}{|c|}{$\begin{array}{c}\text { Physical activity level } \\
\end{array}$} & \\
\hline & \multicolumn{2}{|c|}{ Inadequate } & \multicolumn{2}{|c|}{ Adequate } & & \\
\hline & $\mathbf{n}$ & $\%$ & $\mathbf{n}$ & $\%$ & & $\Sigma$ \\
\hline 12 years & 53 & 15.5 & 288 & 84.5 & 341 & \\
\hline 13 years & 69 & 28.3 & 175 & 71.7 & 244 & \\
\hline 14 years & 74 & 34.4 & 141 & 65.6 & 215 & \\
\hline \multicolumn{7}{|c|}{$\chi^{2}=28.110, \mathrm{df}=2, \mathrm{p}<0.05$} \\
\hline \multirow{3}{*}{ Sex } & \multicolumn{4}{|c|}{ Physical activity level } & \multirow{3}{*}{\multicolumn{2}{|c|}{$\Sigma$}} \\
\hline & \multicolumn{2}{|c|}{ Inadequate } & \multicolumn{2}{|c|}{ Adequate } & & \\
\hline & $\mathbf{n}$ & $\%$ & $\mathbf{n}$ & $\%$ & & \\
\hline Male & 76 & 16.8 & 377 & 83.2 & 453 & \\
\hline Female & 120 & 34.6 & 227 & 65.4 & 347 & \\
\hline \multicolumn{7}{|c|}{$\chi^{2}=33.675, \mathrm{df}=1, \mathrm{p}<0.05$} \\
\hline \multirow{3}{*}{ BMI } & \multicolumn{4}{|c|}{ Physical activity level } & \multirow{3}{*}{\multicolumn{2}{|c|}{$\Sigma$}} \\
\hline & \multicolumn{2}{|c|}{ Inadequate } & \multicolumn{2}{|c|}{ Adequate } & & \\
\hline & $\mathbf{n}$ & $\%$ & $\mathbf{n}$ & $\%$ & & \\
\hline Underweight & 105 & 25.3 & 310 & 74.7 & 415 & \\
\hline Normal & 54 & 26.5 & 150 & 73.5 & 204 & \\
\hline Overweight & 37 & 20.4 & 144 & 79.6 & 181 & \\
\hline \multicolumn{7}{|c|}{$\chi^{2}=2.184, \mathrm{df}=2, \mathrm{p}>0.05, \mathrm{r}=0.03$} \\
\hline \multirow{3}{*}{$\begin{array}{l}\text { Screen time } \\
\text { duration }\end{array}$} & \multicolumn{4}{|c|}{ Physical activity level } & \multirow{3}{*}{\multicolumn{2}{|c|}{$\Sigma$}} \\
\hline & \multicolumn{2}{|c|}{ Inadequate } & \multicolumn{2}{|c|}{ Adequate } & & \\
\hline & $\mathbf{n}$ & $\%$ & $\mathbf{n}$ & $\%$ & & \\
\hline 1-2 hours & 109 & 23.0 & 364 & 77 & 473 & \\
\hline $2-3$ hours & 46 & 24.0 & 146 & 76 & 192 & \\
\hline $\begin{array}{l}\text { More than } 4 \\
\text { hours }\end{array}$ & 16 & 23.2 & 53 & 76.8 & 69 & \\
\hline $\begin{array}{l}\text { Do not watch } \\
\text { T.V }\end{array}$ & 25 & 37.9 & 41 & 62.1 & 66 & \\
\hline Total & 196 & 24.5 & 604 & 75.5 & 800 & \\
\hline & & $=7.023, \mathrm{df}$ & $>0.05, r$ & & & \\
\hline
\end{tabular}

From the table below, frequency of physical activity progressively decreased across all the age groups as the age increased. The low frequency of physical activity $(15.5 \%)$ was found among 12-year age group, and more increased frequency (34.4\%) was observed among 14-year age group, while adequate frequency of physical activity $(84.5 \%)$ was found among 12-year age group. It had decreased to a mere $17.2 \%$ among 14-year age group. Frequency of physical activity was significantly associated with age groups.

A significant association was found between sex and frequency of physical activity $(\mathrm{p}<0.05)$. It can be seen that more male respondents had more adequate frequency of physical activity $(83.2 \%)$ than female ones $(65.4 \%)$. Also, females as compared to males had more inadequate frequency of physical activity (34.6\%).

The study demonstrated a large number of underweight students had adequate frequency of physical activity (74.7\%), while only a small number of overweight students had inadequate frequency of physical activity (20.4\%). Weight was not significantly related to frequency of physical activity $(\mathrm{p}>0.05)$. 
However, a weak positive correlation existed between these variables.

Along with this, the majority of the students with adequate physical activity had recommended screen time duration, i.e., between 1-2 hours. Meanwhile, the students with good screen time duration $(23.3 \%)$ had inadequate frequency of physical activity. Most of the students $(76.8 \%)$ with good screen time duration could do physical activity adequately. The association between frequency of physical activity and screen time duration was not significant ( $\mathrm{p}$ $>0.05)$ and negative $(r=-.056)$.

\section{DISCUSSION}

Research conducted in Canada among children between $8-13$ years old $(n=$ $401 ; 194$ boys and 207 girls) reported that a significant decrease in frequency of physical activity was found along older ages (Sherar et al., 2007). A review study on diet, physical activity, and inactivity in children and adolescents (5-18 years of age) found that frequency of physical activity decreased as ages got older (Leech, McNaughton and Timperio, 2014). In India, a similar study among children around 518 years old showed also support the current results (Swaminathan et al., 2011). There was an increase in the academic burden that caused students not able to have sufficient time for being physically active. The increase in academic burden also leads to decrease in time for physical activities; in turn, it could be the reason that worsens the situation.

With regards to physical activity and sex, among students aged 12 to 14 years in China, a larger number of males had higher frequency of physical activity (Shi et al., 2006). Another study in Saskatchewan reported a significant association between increasing age and decreasing physical activity among school children (Sherar et $a l .$, 2007). Along with this, a study in Spain concluded that among students aged 12-18 years, $26.2 \%$ of the whole boys and $46 \%$ of the total girls could not meet adequate frequency of physical activity (SerranoSanchez et al., 2011). Studies done in Nigeria and India are consistent with the facts that the patterns and frequency of physical activity among schoolboy adolescents varied by sex. The frequency of physical activity in males was marginally higher compared to females (Oyeyemi, Ishaku, Oyekola et al., 2016; Swaminathan et al., 2011). The findings are also consistent with the current study, in which boys were more physically active compared to girls. Similarly, in another study regarding patterns of physical activity behavior, higher numbers of male students engaged in high frequency of physical activity compared to girls who did not show any such trend (Smith et al., 2016). In another cross-sectional study on 456 college students aged 18-28 years in Saudi Arabia, almost half of the female students reported physical inactivity (Alzamil et al., 2019).

In the same way as the current study, research among urban children aged 8-15 years in South Indian reported that moderate to vigorous frequency of physical activity was higher in boys than in girls (Swaminathan et al., 2011). A study among school children aged $10-19$ years $(n=1714$; $55 \%$ males and $45 \%$ females) in Ambala, Haryana, reported that the frequency of physical activity remained consistently less than 60 minutes per day in both sexes. Around 40\% adolescents reported > 1680 METs/week, and $11 \%$ adolescents spent > 2520 METs/week, respectively (Pathak et al., 2017).

As whether physical activity was related to BMI was concerned, some studies showed similar results while some had discordant results. A study in Seychells stated frequency of physical activity and weight had a significantly inverse relationship (Bovet, Auguste and Burdette, 2007). Another study in Iran reported that physical activity and weight had a significantly inverse association as well (Kelishadi et al., 2007). However, this study is not in line with the present study. In 
Ghana, children who had more weight were less physically active than children with normal weight $(\mathrm{AOR}=1.44 ; 95 \% \mathrm{CI}=$ 1.07, 1.94) (Aryeetey, Lartey, Marquis et al., 2017). A study among school students in Bhubaneswar city, India mentioned low frequency of physical activity was significantly associated with overweight, while the current study showed different results (Hota et al., 2015). In contrast, research reported that BMI was not significantly associated with frequency of physical activity, and so did the present study (Goyal et al., 2011).

The major current findings conveyed that most of the students had adequate frequency of physical activity and good screen time duration as recommended by the guidelines (Encyclopedia, 2020).

With regard to physical activity, a study in Dakar reported that $57 \%$ of the students were involved in moderate physical activity, while $43 \%$ had low PAL (Diouf et al., 2016). Another study in Greece reported similar results to the present study that school children conducted adequate frequency of physical activity (Diouf et al., 2016; Tsioufis et al., 2011). The PAQ-C questionnaire in the current study tends to overestimate moderate frequency of physical activity and screen time duration compared to the measured intensity of physical activity (Peters et al., 2010). By contrast, the 2016 India Report on physical activity in children and youth stated that only about $38 \%$ of children between 13-15 years old met the recommended PAL (Katapally et al., 2016). Similar results have been found in a few other studies conducted in West Bengal and Nagpur, India (Lahiri et al., 2019; Ronghe et al., 2016).

Various studies from Mexico and India have reported that school adolescents did not adhere to the recommended screen time limit. Most of them had average screen duration of 3 hours per day and used mobile phones for the entertainment purposes (Dubey et al., 2018; Lahiri et al., 2019; Morales-Ruán et al., 2009). Another study in Australia reported about 63\% adolescents used electronic devices for more than 2 hours per day (Hysing et al., 2015). These results are in line with the current study where $24 \%$ of the students had screen time duration of more than 2 hours per day, and $8.6 \%$ had screen time duration of more than 4 hours per day.

The mean screen time duration was more than 2 hours per day in both male and female students. However, it was higher in males than females probably due to easy availability and accessibility to devices and lack of recreational facilities in residential areas, leading children to be compelled with using electronic devices for recreational purposes (Shah, Fahey, Soni et al., 2019). In rural areas of Western India, the average screen time duration was 2.7 hours ( $\mathrm{SD}=$ 1.7). This finding accords with the present study.

As for BMI status and time duration, in Ireland, a longitudinal study reported longer screen time in overweight children than normal children (O'Brien, Issartel and Belton, 2018). Consistent with the current study, a similar study conducted in Tamil Nadu, India conveyed no significant association between BMI and screen time (S. Santha Kumar, 2019). Regardless of BMI, students had an average screen time of 2.6 hours per day (Nawab et al., 2016).

A study among school adolescents in the United States showed that less exposure to screen and more adequate frequency of physical activity were associated with lower obesity (Boone et al., 2007). In contrast, this current study showed screen time was not associated with frequency of physical activity. Similarly, various other studies among school adolescents in Spain, the United Kingdom, and the United States confirmed children having less screen time were more physically active (Marshall et al., 2004; Sandercock, Ogunleye and Voss, 2012; Serrano-Sanchez et al., 2011). However, in Ireland, research found that screen time duration was far unrelated to frequency of physical activity (O'Brien et al., 2018). In 
India, some studies contrastingly showed screen time was correlated with frequency of physical activities (Boone et al., 2007; Dubey et al., 2018).

\section{CONCLUSION}

Almost a quarter of the students had inadequate frequency of physical activity, while almost more than half of the respondents followed the recommended screen time limit. Screen time was not significantly correlated with frequency of physical activity.

For children having inadequate frequency of physical activity, interventions can be introduced at family, school, and community levels, along with strong political commitment from the government. Parents can be role models, teaching them the benefits of being physically active. Increasing the duration and frequency of physical education classes at schools, provision of proper infrastructure and safe environment in residential areas are some ways to ensure children's physical activity. Teachers should educate the students about the importance of taking proper diet as well as limiting screen time on electronic devices. Besides, they need to motivate them to perform more physical activity (CDC, 2011). Despite the results, the present study may have some limitations due to a short period of data collection using the PAQ-C questionnaire, thus leading to bias. Apart from this, since the study was conducted only on adolescents enrolled to schools, the previous results might not be generated to the entire adolescent population of the same age group.

\section{REFERENCES}

Alzamil HA, Alhakbany MA, Alfadda NA, Almusallam SM and Al-Hazzaa HM (2019) A profile of physical activity, sedentary behaviors, sleep, and dietary habits of Saudi college female students. Journal offamily \& community medicine 26:1.
https://doi.org/10.4103/jfcm.JFCM _58_18

Aryeetey R, Lartey A, Marquis GS, Nti H, Colecraft E and Brown P (2017) Prevalence and predictors of overweight and obesity among school-aged children in urban Ghana. BMC obesity4:1-8. https://doi.org/10.1186/s40608017-0174-0

Benítez-Porres J, López-Fernández I, Raya JF, Álvarez Carnero S, Alvero-Cruz JR and Álvarez Carnero E (2016) Reliability and Validity of the PAQC Questionnaire to Assess Physical Activity in Children. Journal of School Health86:677-685. https://doi.org/10.1111/josh.12418

Boone JE, Gordon-Larsen P, Adair LS and Popkin BM (2007) Screen time and physical activity during adolescence: longitudinal effects on obesity in young adulthood. International Journal of Behavioral Nutrition and Physical Activity4:26. https://doi.org/10.1186/1479-58684-26

Bovet P, Auguste R and Burdette H (2007) Strong inverse association between physical fitness and overweight in adolescents: a large school-based survey. International Journal of Behavioral Nutrition and Physical Activity4:24. https://doi.org/10.1186/1479-58684-24

Canadian Paediatric Society DHTF, Ottawa, Ontario, (2017) Screen time and young children: promoting health and development in a digital world, Oxford University Press US. control cfd (2011) The CDC Guide to Strategies to Increase Physical Activity in the Community.

Diouf A, Thiam M, Idohou-Dossou N, Diongue O, Mégné N, Diallo K, Sembène PM and Wade S (2016) Physical activity level and sedentary behaviors among public school children in dakar (senegal) 
measured by paq-c and accelerometer: Preliminary results. International journal of environmental research and public health13:998.

https://doi.org/10.3390/ijerph13100 998

Dubey M, Nongkynrih B, Gupta SK, Kalaivani M, Goswami AK and Salve HR (2018) Screen-based media use and screen time assessment among adolescents residing in an Urban Resettlement Colony in New Delhi, India. Journal of family medicine and primary care7:1236. https://doi.org/10.4103/jfmpc.jfmpc _190_18

Encyclopedia MM (2020) Children S. Screen time and children.

Goyal JP, Kumar N, Parmar I, Shah VB and Patel B (2011) Determinants of overweight and obesity in affluent adolescent in Surat City, South Gujarat region, India. Indian journal of community medicine: official publication of Indian Association of Preventive \& Social Medicine36:296.

https://doi.org/10.4103/09700218.91418

Guthold R, Stevens GA, Riley LM and Bull FC (2018) Worldwide trends in insufficient physical activity from 2001 to 2016: a pooled analysis of 358 population-based surveys with 1.9 million participants. The Lancet Global Health6:e1077-e1086. https://doi.org/10.1016/S2214109X(18)30357-7

Hota S, Pangrahi RK, Mahilary N, Mohapatro S, Kumar SV and Mohanty S (2015) Dietary Pattern amongst overweight and obese children, 9-15 years from government school in Bhubaneswar city. IOSR Journal of Dental and Medical Sciences 14:32-36.

Hysing M, Pallesen S, Stormark KM, Jakobsen R, Lundervold AJ and
Sivertsen B (2015) Sleep and use of electronic devices in adolescence: results from a large populationbased study. BMJ open5:e06748. https://doi.org/10.1136/bmjopen2014-006748

Kang H-T, Lee H-R, Shim J-Y, Shin Y-H, Park B-J and Lee Y-J (2010) Association between screen time and metabolic syndrome in children and adolescents in Korea: the 2005 Korean National Health and Nutrition Examination Survey. Diabetes research and clinical practice89:72-78.

https://doi.org/10.1016/j.diabres.20 10.02.016

Katapally TR, Goenka S, Bhawra J, Mani S, Krishnaveni GV, Kehoe SH, Lamkang AS, Raj M and McNutt K (2016) Results from India's 2016 report card on physical activity for children and youth. Journal of physical activity and health13:S176-S182.

https://doi.org/10.1123/jpah.20160393

Kelishadi R, Ardalan G, Gheiratmand R, Gouya MM, Razaghi EM, Delavari A, Majdzadeh $\mathrm{R}$, Heshmat $\mathrm{R}$, Motaghian M and Barekati H (2007) Association of physical activity and dietary behaviours in relation to the body mass index in a national sample of Iranian children and adolescents: CASPIAN Study. Bulletin of the World Health Organization85:19-26. https://doi.org/10.2471/BLT.06.030 783

Kumar B, Robinson R and Till S (2015) Physical activity and health in adolescence, in Clinical Medicine $\mathrm{p}$ 267.

https://doi.org/10.7861/clinmedicin e.15-3-267

Lahiri A, Chakraborty A, Dasgupta U, Roy AKS and Bhattacharyya K (2019) Effect of dietary habit and physical activity on overnutrition of 
schoolgoing adolescents: A longitudinal assessment in a rural block of West Bengal. Indian journal of public health63:171. https://doi.org/10.4103/ijph.IJPH_1 59_19

Leech RM, McNaughton SA and Timperio A (2014) The clustering of diet, physical activity and sedentary behavior in children and adolescents: a review. International Journal of Behavioral Nutrition and Physical Activity11:1-9. https://doi.org/10.1186/1479-586811-4

Manios Y, Androutsos O, Moschonis G, Birbilis M, Maragkopoulou K, Giannopoulou A, Argyri E and Kourlaba G (2013) Criterion validity of the Physical Activity Questionnaire for Schoolchildren (PAQ-S) in assessing physical activity levels: the Healthy Growth Study. J Sports Med Phys Fitness 53:502-508.

Marshall SJ, Biddle SJ, Gorely T, Cameron $\mathrm{N}$ and Murdey I (2004) Relationships between media use, body fatness and physical activity in children and youth: a meta-analysis. International journal of obesity28:1238-1246.

https://doi.org/10.1038/sj.ijo.08027 06

McKenzie TL, Marshall SJ, Sallis JF and Conway TL (2000) Student activity levels, lesson context, and teacher behavior during middle school physical education. Research quarterly for exercise and sport71:249-259.

https://doi.org/10.1080/02701367.2 000.10608905

Morales-Ruán MdC, Hernández-Prado B, Gómez-Acosta LM, Shamah-Levy $\mathrm{T}$ and Cuevas-Nasu L (2009) Obesity, overweight, screen time and physical activity in Mexican adolescents. salud pública de méxico51:S613-S620.
https://doi.org/10.1590/S003636342009001000016

Nawab T, Khan Z, Khan IM and Ansari MA (2016) Is small town India falling into the nutritional trap of metro cities? A study in school-going adolescents. Journal of family medicine and primary care5:581. https://doi.org/10.4103/22494863.197296

O'Brien W, Issartel J and Belton S (2018) Relationship between physical activity, screen time and weight status among young adolescents. Sports6:57.

https://doi.org/10.3390/sports60300 57

Organization WH (2019) major NCDs and their risk factors

Organization WH (2020) BMI-for-age (519 years)

Oyeyemi AL, Ishaku CM, Oyekola J, Wakawa HD, Lawan A, Yakubu S and Oyeyemi AY (2016) Patterns and associated factors of physical activity among adolescents in Nigeria. PloS one11:e0150142. https://doi.org/10.1371/journal.pon e. 0150142

Pathak R, Singh M, Goyal A, Agarwalla R and Goel R (2017) Pattern and Determinants of Physical Activity in Rural and Urban Adolescents of North India: A Population Based Study. International Journal of Nutrition, Pharmacology, Neurological Diseases7. https://doi.org/10.4103/ijnpnd.ijnpn d_25_17

Peters TM, Shu X-O, Moore SC, Xiang YB, Yang G, Ekelund U, Liu D-K, Tan Y-T, Ji B-T and Schatzkin AS (2010) Validity of a physical activity questionnaire in Shanghai. Medicine and science in sports and exercise 42: 2222.

https://doi.org/10.1249/MSS.0b013 e3181e1fcd5

Ronghe DR, Gotmare DN and Kawishwar DS (2016) Physical activity level of 
school children of age 10-13 years. International Journal of Biomedical and Advance Research 7:281. https://doi.org/10.7439/ijbar.v7i6.3 330

S. Santha Kumar SAS (2019) Association of screen time with physical activity and BMI in middle school children at Tamil Nadu, India. International Journal of Contemporary Pediatrics:78-83.

https://doi.org/10.18203/2349-

3291.ijcp20195730

Sallis JF, Prochaska JJ and Taylor WC (2000) A review of correlates of physical activity of children and adolescents. Medicine and science in sports and exercise32:963-975. https://doi.org/10.1097/00005768200005000-00014

Sandercock GR, Ogunleye A and Voss C (2012) Screen time and physical activity in youth: thief of time or lifestyle choice? Journal of Physical Activity and Health9:977-984. https://doi.org/10.1123/jpah.9.7.97 7

Serrano-Sanchez JA, Martí-Trujillo S, Lera-Navarro A, Dorado-García C, González-Henríquez JJ and Sanchís-Moysi J (2011) Associations between screen time and physical activity among Spanish adolescents. PloS one6:e24453.

https://doi.org/10.1371/journal.pon e.0024453

Shah RR, Fahey NM, Soni AV, Phatak AG and Nimbalkar SM (2019) Screen time usage among preschoolers aged 2-6 in rural Western India: A cross-sectional study. Journal of Family Medicine and Primary Care8:1999.

https://doi.org/10.4103/jfmpc.jfmpc _206_19

Sherar LB, Esliger DW, Baxter-Jones AD and Tremblay MS (2007) Age and gender differences in youth physical activity: does physical maturity matter? Medicine \& Science in Sports \& Exercise39:830-835. https://doi.org/10.1249/mss.0b013e $3180335 \mathrm{c} 3 \mathrm{c}$

Shi Z, Lien N, Kumar BN and HolmboeOttesen G (2006) Physical activity and associated socio-demographic factors among school adolescents in Jiangsu Province, China. Preventive medicine 43:218-221.

https://doi.org/10.1016/j.ypmed.20 06.04.017

Sisson SB, Broyles ST, Baker BL and Katzmarzyk PT (2010) Screen time, physical activity, and overweight in US youth: National Survey of Children's Health 2003. Journal of Adolescent Health47:309-311. https://doi.org/10.1016/j.jadohealth. 2010.02.016

Smith C, Hannon JC, Brusseau TA, Fu Y and Burns RD (2016) Physical activity behavior patterns during school leisure time in children. International Journal of Kinesiology and Sports Science 4:17-25. https://doi.org/10.7575/aiac.ijkss.v. 4n. $1 \mathrm{p} .17$

Swaminathan S, Selvam S, Thomas T, Kurpad AV and Vaz M (2011) Longitudinal trends in physical activity patterns in selected urban south Indian school children. The Indian Journal of Medical Research134:174.

Tsioufis C, Kyvelou S, Tsiachris D, Tolis P, Hararis G, Koufakis N, Psaltopoulou T, Panagiotakos D, Kokkinos P and Stefanadis C (2011) Relation between physical activity and blood pressure levels in young Greek adolescents: the Leontio Lyceum Study. European Journal of Public Health21:63-68. https://doi.org/10.1093/eurpub/ckq 006 